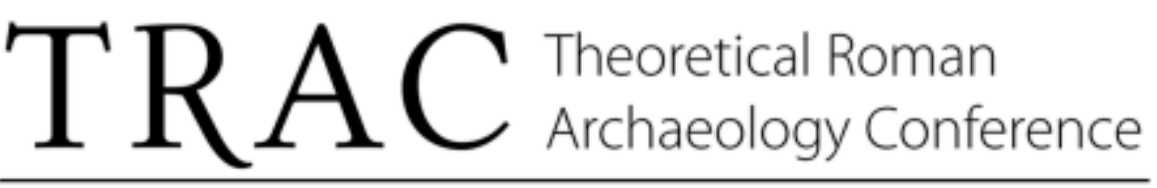 \\ www.trac.org.uk
}

\section{Paper Information:}

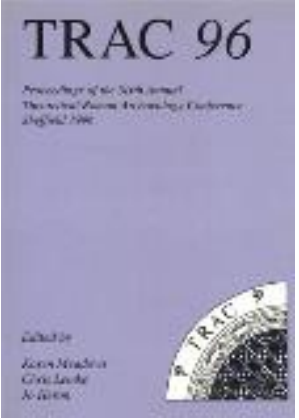

DOI: http://doi.org/10.16995/TRAC1996 2228

Publication Date: 11 April 1997

Title: The Enemy Without, The Enemy Within: More

Thoughts on Images of Barbarians in Greek and

Roman Art

Author: I. Ferris

Pages: 22-28

\section{Volume Information:}

Meadows, K., Lemke, C., and Heron, J. (eds) 1997. TRAC 96:

Proceedings of the Sixth Annual Theoretical Roman Archaeology

Conference, Sheffield 1996. Oxford: Oxbow Books.

\section{Copyright and Hardcopy Editions:}

The following paper was originally published in print format by Oxbow Books for TRAC. Hard copy editions of this volume may still be available, and can be purchased direct from Oxbow at http://www.oxbowbooks.com.

TRAC has now made this paper available as Open Access through an agreement with the publisher. Copyright remains with TRAC and the individual author(s), and all use or quotation of this paper and/or its contents must be acknowledged. This paper was released in digital Open Access format in April 2013. 


\title{
4. The Enemy Without, The Enemy Within: More Thoughts on Images of Barbarians in Greek and Roman Art
}

\author{
by I. Ferris
}

In two previous papers on different, but related, aspects of the study of images of barbarians in Classical art (Ferris 1995 and forthcoming) it has been argued that analysis of these images can provide numerous insights into the social, political and cultural contexts in which the images were created.

In the first paper (Ferris 1995), an attempt was made to analyse and contextualise a number of images generated within a specifically military context in Roman Britain. In the second paper (Ferris forthcoming), study was concentrated on analysing a wide range of motifs of barbarian defeat, subjection, mistreatment, humiliation, mutilation and death in terms of the conscious manipulation of the sexuality of certain images of the barbarian protagonists, whether men, women or children.

In this present paper a contrastive approach will be taken to the discussion of two quite different barbarian images, one with origins in the Greek world, though often considered by some authorities to encapsulate the perceived philosophical ethos of a wider Classical mission (cf. Henig 1995:22), and the other from the late Roman period, indeed from what should, more properly, be called Late Antiquity. While quite obviously not directly comparable, discussion of the two together may allow some communality of issues to be identified and addressed, particularly with regard to the significance of the media in which the images appear and to the conceptual boundaries created by the images' framing, viewed in relation to the environments in which they were created and consumed.

The first image to be considered in detail here is the sculpture most commonly known as 'The Ludovisi Gauls' or 'The Suicidal Gaul with Wife' (sic) (now in the Museo Nazionale Romano in Rome). This work is considered by most authorities to be a Roman copy in marble of a Greek bronze, dating from c230-220 BC. In all probability, it formed part of a programme of sculptures commissioned by Attalos I of Pergamon for victory monuments at Pergamon and elsewhere to commemorate triumphs over Gauls and Seleucids (for a full discussion of the background see Pollitt 1986:83-85). The context and setting of these sculptures will be considered below.

Leaving aside the nature of the evident restoration work on the sculpture, the work is otherwise complete. The sculpture is well described by Pollitt:

the chieftain has stabbed his wife under the left arm, and as she collapses he drives his sword into his own neck just inside the collar bone. Blood is...shown flowing from the wound. The wife's mouth is open in a dying gasp, and her eyes begin to close; her husband glances dramatically upward in final defiance at what we can assume was an equestrian opponent. A Gallic oval shield and the sheath of the sword lie at their feet (Pollitt 1986:86-9). 
Pollitt (1986) also noted what he called 'the magnification and intensification of anatomical features' in this work, as in others in the series. This stylistic device is used to particularly dramatic effect in the figure of the man, who is naked apart from a short cloak draped over his shoulders and arranged behind his back, away from his sword-bearing arm. His torso and limbs are tensed and straining, his body is wild power personified. In evident contrast, the woman is fully clothed in an elaborate fringed garment. Her limbs appear limp and marble-smooth and she would already seem to be beyond life and beyond the containing realities of the physical body. Her threatening wildness has been extinguished. The binary divisions in this work, between male/female, naked/clothed, unfettered wildness/tamed wildness and life/death, are not easily separated by the viewer's initial gaze, making the message of this work more complex than a simple representation of defeat.

It is not only the woman's life that has been here ended. Natalie Boymel-Kampen has noted how barbarian women in acts of submission are sometimes meant to symbolise a community in defeat, a potential reproductive future that has been curtailed or affected by war (Boymel-Kampen 199 1:245), and I have developed this line of research in one of my previous papers on barbarian imagery (Ferris 1995). The death of the Gaulish woman on the Attalid sculpture represents the extinguishing of potential life and thus a barren and sterile future. The clothing of her body perhaps alludes to her now being non-sexual, an interpretation that contrasts with, but does not contradict, my previous reading of the sexuality of the naked female barbarian (Ferris 1995:26-7).

This sculpture is evidently intended to be viewed from all angles, the nuances of the moment of drama, here caught in stasis, being subtly altered by the shifting gaze of the spectator. Pollitt has summarised the variously conjectured reconstructions of the sculptural groups that made up the Attalid monuments (Pollitt 1986:89-95), but pointed out that there is really no sure way of knowing which sculptures, firstly, can be assigned with certainty to the monuments; secondly, which sculptures would belong to which monument; and thirdly, how these assigned sculptures would be grouped together and what layout of groups was found at each site.

There does, however, seem to be a consensus that the groupings of sculptures at the monuments, whatever they had been, were made so as to achieve a theatrical effect. Pollitt writes of one hypothetical grouping:

walking around or through the group must have been like walking through a battlefield when the battle is nearly over. Surrounding one were bleeding corpses, dying warriors, and a few pockets of final resistance. The work seems to have been designed to provoke in its viewers an imaginary experience (Pollitt 1986:92).

This scene is significant in that in Greek and Roman art there is, to my knowledge, no similar work in which a barbarian woman is portrayed being killed or in the act of dying, and although on a number of Roman artworks (see Ferris 1995) sundry acts of brutalisation or forced submission of women are shown, as Natalie Boymel-Kampen has pointed out, these works are relatively few in number (Boymel Kampen 1991:245 n.5). Suicide is also an uncommon theme, though suicidal barbarian chieftains do appear in a number of instances in battle scenes on sarcophagi. An historically-attested suicide scene appears on Trajan's Column (Scene No. CXLV), and shows the self-inflicted death of Decebalus, just moments before the arrival of the Roman forces at Sarmizegethusa. Yet this particular portrayal must be viewed as historical reportage, rather than as somehow symbolic.

In the suicide-pact sculpture, if that is indeed what it represents, the fate of the barbarian protagonists is undeniably self-determined and, within the invisible framework provided by the con- 
straining but defining momentum of war and battle, autonomous. As Elisabeth Bronfen has noted in her study Over Her Dead Body. Death, Femininity and the Aesthetic, "suicide implies an authorship of one's own life, a form of writing the self and writing death that is ambivalently poised between self-construction and self-destruction." (Bronfen 1992:142). But it is equally true to say that to the viewer's gaze a different reading could be made, where death marks the end of individuality and not its apotheosis. Again, as Bronfen has pointed out, "death threatens to put an end to differentiation. Because the corpse is a figure without any distinguishing facial traits of its own, one could say that semiotically it serves as an arbitrary, empty, interchangeable sign, an interminable surface for projections." (Bronfen 1992:64).

Gayatari Spivak, in her essay Can the Subaltern Speak?, discussed ways of representing the Hindu custom of suttee or suti, where a widow would throw herself upon her husband's funeral pyre, a practice banned by the British in India in 1828 . Jacoby in a review article about post-colonial studies in general, wrote that:

Spivak offers two sentences that capture the dilemma. The British actions might be viewed as "White men saving brown women from brown men". The Indian nationalist might respond, "The women actually wanted to die." Neither formulation is satisfactory; and neither allows the women to speak. Spivak...seems to suggest that the British turned a ritual into a crime; and that suttee might be read as a perverse act of freedom, even of resistance (Jacoby 1995:17).

Another view, according to Donaldson, is that "women who succeed at taking their own lives outwit and reject their 'feminine' role at the only price possible: their deaths" (Donaldson 1992:30). As Donaldson goes on to say in relation to the suicide of Bertha in Jane Eyre, "[this] constitutes an act of resistance not only to her status as a woman in a patriarchal culture but also as a colonized object" (Donaldson 1992:30). Choosing biological death in such a situation allows escape from what Bulhan has called, in contrast, "psychological and social death" (Bulhan 1985:122), while it may also be construed as subverting the gaze of colonial desire (Young 1995).

The cultural context of suicide is here considered at length, because it seems to be somehow pertinent to the way in which the discussion of the suicide pact sculpture has been previously conducted. The event depicted may have had some basis in fact, a particularly noteworthy incident reported from the battlefield. Such incidents involving Celts or Gauls, may have been attested in previous battles or may have been part of an ethnography or mythology of barbarian behaviour. The suicide pact could be taken as a final act of resistance and defiance, a grand gesture or an accepted, culturally-conditioned and expected response to defeat. It could also be interpreted as an act of sheer desperation, carried out in fear of the consequences of capture, torture or rape. The acquiescence of the woman is always assumed, she is usually thought of as having died at the man's hand. What would such an act tell us about gender relations among these barbarians? By her death she has seemingly become silent and forever passive.

It is instructive here to consider certain aspects of the creation of Greek literary narratives, as dissected and discussed by Edith Hall in her book Inventing the Barbarian. Greek Self-Definition Through Tragedy (Hall 1989). In creating stereotypical barbarian characters, Greek writers often used the description of their supposedly flawed psychological profiles and their foreign and fantastical material attributes as a way to highlight, in contrast with, and more properly, in opposition to, the admirable characteristics of the ideal Greek. Yet, as Hall points out, this setting up of oppositions was not necessarily simplistic: 
the Greeks view of the barbarian was inherently contradictory, for civilisation's view of itself as in a process of linear progression is never unquestioned; the rise paradoxically, is seen also as a fall. The retrospective vision incorporates the idea not only of primitive chaos, but of a more virtuous era, when men were nearer to the gods....This schizophrenic vision of inferiority and of utopia gives rise to an inherently contradictory portrayal of the barbarian world (Hall 1989:149).

I would suggest that it is a visualisation of such schizophrenia that gives the statues of the Attalid Gauls their magnetic power. They are essays in both victory and in regret.

Jane Webster has recently suggested that the writings of certain Classical ethnographers created two strains of colonial discourse, one 'the discourse of savagery', the other 'the discourse of the timeless primitive' (Webster 1996), and it can perhaps be argued that both literary and historical/ethnographic narratives and artistic imagery were consciously or subconsciously structured in this way.

It is not intended to argue here that the same symbolic value was placed on the images of the Attalid Gauls when these works, through removal from their original context and the cultural milieu in which they had originally been created and consumed, were copied and culturally relocated, both physically and psychologically, in the Roman world. Quite the opposite in fact.

It has been argued elsewhere that while there is a broad chronological trend towards the dehumanisation of the barbarian in Roman art from the time of Marcus Aurelius onwards (Ferris 1995), even before this period there is little evidence that the Roman psyche, consciously or subconsciously, harboured the kind of schizophrenic nostalgia for a primitive past, as projected onto the image of the unfettered barbarian, that Hall proposes for the Greeks.

Attention will now be focused on the second image, that is the portrayal of the barbarian general Stilicho and his family on the ivory and gilt diptych now in Monza Cathedral Treasury. As Strong has noted, these diptychs were made as presents to be given by those of consular status "to provinces, cities, Senate, magistrates, and people". These were thus exclusive works of art, depicting precisely controlled and authored images, both at the same time potentially highly personal and yet, by reason of the motives for their commissioning, very public (1976:165).

While I am here calling Stilicho a barbarian, to be precise, he was only a semi-barbarian, having a Vandal father and a Roman mother. His marriage in c AD 384 to Serena, Theodosius's niece and adopted daughter, brought him into the imperial family and symbolised the by then necessary and symbiotic relationship between Roman civil power and the military power of certain barbarian groups.

In the case of Stilicho and his family it may thus be suggested that, in contrast to nearly all other images of barbarians, here is a case of barbarian self-authorship that needs to be analysed with this in mind. Of course, it could be argued that rather than being images, these are portraits of historically-attested individuals and not simply ciphers or stereotypes. Nevertheless they appear to us, if in fact they can be said to appear to us at all, filtered through sanctioned and censored images.

On one leaf of the diptych Stilicho stands alone, upright but stiff and formal, holding a spear and shield, in a pose similar to that of the barbarian bodyguards on the late-fourth century silver missorium of Theodosius I (now in the Academia de la Historia, Madrid). He looks straight ahead, his bearded face expressionless. Such a transcendent pose is a typical signifier of latent or absolute power in the often theatrical official ceremonies and displays of Late Antiquity, as has been pointed out by Simon Ellis (Ellis 1991:129). Here a sense of power is conveyed by the lack of movement in the work and in the static, framed nature of its composition.

Stilicho is depicted against an elaborate architectural facade or interior. He is framed and con- 
tained not only within the architectural space but also by the border of the leaf, though his feet are allowed to project out from the frame, the only implication of movement in the work. On the other leaf appear his wife Serena and their son Eucharius, again posed formally facing the front and devoid of expression, she holding a flower and he a book or tablet. The architectural setting is repeated. There must certainly have been some particular significance intended here by the portrayal of Stilicho in military garb, as most of the other surviving consular diptychs show the consuls overseeing public games and ceremonies.

The presence of Serena and Eucharius would appear to be significant. Depictions of barbarian children are relatively rare in Roman art (Ferris 1995:28), and when they do appear, they are often there to act as ciphers for the disruption of future lineage and for fertility curtailed or negated by defeat. Conversely, images of the Roman family could be used in a similar way to suggest strength through fertility, the continuity of lineage, and as evidence of a seamless future. The most marked example of the latter is in the art of the Augustan age (Zanker 1988). It would seem that Serena and Eucharius, in company with Stilicho, are present here to further strengthen and underpin the message of stability in a similar way. They symbolise the key role that certain barbarian groups were now expected to play in the future of the Roman administration.

Ellis has written on the use and control of architectural space by the late Roman aristocrat:

[he] carefully defined the architectural context in which his public encounters took place. He separated public and private and used the architecture to manipulate social encounters in a way that had never been done in earlier periods. The depth to which a guest penetrated the building and the route he took emphasized his degree of intimacy with the owner (Ellis 1991:123).

In the same way, the viewers of the diptych would perceive themselves negotiating access to, and eventually being admitted into, an inner sanctum, the seat of power. This effect is achieved through a combination of the artistic medium, the framing and the composition of the diptych. The scale and intimacy of the diptych, and the rarity and exclusiveness of the material from which it is made, allow the viewer the sensation of attending a private audience. The viewer is invited to enter an artistic setting akin to a form of memory palace (Spence 1985), moving inexorably from room to room, from outer room into inner sanctum, there to encounter Stilicho and his family, an image of both latent power and of security. While this is very much an intimate and private work of art, certainly in the way it must be viewed, its interpretation requires the same degree of image and audience interplay that underpins the creation of more public art.

Finally, to turn to the contrasting of these two seemingly unconnected works. The most significant contrast between the two works would seem to be the way in which the setting of the protagonists has been created to enhance the overall message of each image. Yet these very different settings in many respects are used to convey similar messages.

In terms of the framing of the two images, it is useful to analyse them in reference to the five modes of framing used in Greek art, as defined by Hurwit (1977). The Suicidal Gauls sculpture could be defined as being in the 'open mode', with the frame being represented by the physical limits of the sculpture itself, or by the architectural setting in which it would originally have been displayed. Such an open mode suggests to the viewer "a perception of limit transcended, of extension rather than closure, of release rather than confinement" (Hurwit 1977:5). Open form, through its denial of a formal border, also helps activate the surface of the sculpture, "lending it the qualities of energy, corporeality, extension or power" (Hurwit 1977:10). Many elements of the sculpture - 
its scale, its inherent sense of free movement created by its multiple viewing options, the flowing, natural lines of the figures' stances, and the sense of the sheer physical power of the man's body - combine to create a vision of unfettered nature or primitive wildness. And yet that wildness is being tamed by death, by a very public death, captured in stasis but prolonged by its very capture.

In contrast, the Stilicho diptych could be argued to correspond to the 'closed mode', where "values of stability and order are achieved by the subordination of the image to the frame" (Hurwit 1977:1). The formality of the framing enhances the sense of stillness and of latent power. The sense of power is further enhanced by the formal framing of the central images by an architectural setting.

Again, allusion has been made to the way in which the image of the female barbarian on the Attalid sculpture may have been used to represent curtailed fertility and by implication a sterile future for the barbarians in general. In contrast the presence of Serena on the ivory diptych, in company with her son and her barbarian husband, conveys the completely opposite message. It may be that her holding aloft a flower further symbolises her fertility.

On both works there are depicted culturally-significant attributes in the form of traditional weapons; respectively, the sword, (though it may be a reconstruction), sheath and shield of the suicidal male Gaul and the shield and spear of Stilicho. It would seem that in the former case the weapons help to consolidate the creation of an image of otherness, they are also either discarded or dropped, or are being turned upon their owners as instruments of self-destruction. In the latter case Stilicho's spear and shield are held at ease, in the stance of a guard or protector. There is a further possible significance in the depiction of the shield on the Stilicho diptych, in that such shields, themselves derived from Germanic types and adopted as Roman military equipment, by then played an active role in the ceremony of imperial accession, "in that the ceremony of raising the emperor on the shield was a Germanic one” (MacCormack 1981:217), as were other elements of state celebrations of victory by this time (cf. McCormick 1986:114-5).

Curiously, the stressing of barbarian roots and cultural heritage in both works, as originally conceived, is possibly being used to evoke in the viewer a nostalgia for a strength of character, a primitivism, that perhaps is no longer perceived as being present within respectively Greek and Roman character and society. It is interesting to note that there is no equivalent pictorial shorthand used to allude to the female barbarian, and thus through her usual portrayal in bodily form she remains permanently objectified.

Dyer has observed that while stereotypes, and that is one way of defining some images of barbarians in both Greek and Roman art, are:

a very simple, striking, easily-grasped form of representation they are none the less capable of condensing a great deal of complex information and a host of connotations....the often observed 'simplicity' of stereotypes is deceptive (Dyer 1993:12).

Such an observation would seem to be borne out by the on-going analysis of images of barbarians in Classical art. In the case studies here presented it may be argued that the enemy without has been transformed into the enemy within.

\section{Acknowledgements}

Thanks to Lynne Bevan for commenting on a draft of this paper and to Simon Ellis and Simon Esmonde Cleary for comments made on certain aspects of the paper after its presentation at the TRAC conference. Thanks also to the anonymous referee whose observations have been most helpful. 


\section{Bibliography}

Boymel-Kampen, N. 1991. Between public and private: women as historical subjects in Roman art. In Women's History and Ancient History (ed. S. Pomeroy). North Carolina: University of North Carolina Press, pp. 218-248.

Bronfen, E. 1992. Over Her Dead Body. Death, Femininity and the Aesthetic. Manchester: Manchester University Press.

Bulhan, H. A. 1985. Frantz Fanon and the Psychology of Oppression. London: Plenum.

Donaldson, L. E. 1992. Decolonizing Feminisms. Race, Gender and Empire-Building. North Carolina: University of North Carolina Press.

Dyer, R. 1993. The Matter of Images. Essays on Representation. London: Routledge.

Ellis, S. 1991. Power, architecture, and decor: how the Late Roman aristocrat appeared to his guests. In Roman Art in the Private Sphere (ed. E. K. Gazda). Michigan: University of Michigan Press., pp. 117-134

Ferris, I. M. 1995. Insignificant others; images of barbarians on military art from Roman Britain. In TRAC 94 Proceedings of the Fourth Annual Theoretical Roman Archaeology Conference, Durham 1994 (eds S. Cottam, D. Dungworth, S. Scott and J. Taylor), Oxford: Oxbow, pp. 24-31.

Ferris, I. M. forthcoming. Bodies of evidence. The sexuality of barbarians in Roman art. In Sexuality, Society and the Archaeological Record (eds L. Bevan and D. Christodoulou).

Hall, E. 1989. Inventing the Barbarian. Greek Self-Definition Through Tragedy. Oxford: Clarendon Press. Henig, M. 1995. The Art of Roman Britain. London: Batsford.

Hurwit, J. 1977. Image and frame in Greek art. American Journal of Archaeology, 81:1-30.

Jacoby, R. 1995. Colonial writers lost in the post. The Times Higher, December 29 1995: 17.

MacCormack, S. G. 1981. Art and Ceremony in Late Antiquity. California: University of California Press.

McCormick, M. 1986. Eternal Victory. Triumphal Rulership in Late Antiquity, Byzantium, and the Early Medieval West. Cambridge: Cambridge University Press.

Pollitt, J. J. 1986. Art in the Hellenistic Age. Cambridge: Cambridge University Press.

Spence, J. D. 1985. The Memory Palace of Matteo Ricci. London: Faber.

Spivak, G. C. 1988. Can the subaltern speak? In Marxism and the Interpretation of Culture (eds C. Nelson and L. Grossberg). Illinois: University of Illinois Press., pp. 271-313.

Strong, D. 1976. Roman Art. Harmondsworth: Penguin.

Webster, J. 1996. Ethnographic barbarity; colonial discourse and 'Celtic Warrior Societies'. In Roman Imperialism: Post-Colonial Perspectives (eds J. Webster and N. Cooper). Leicester: University of Leicester Archaeology Monographs No. 3, pp. 111-123.

Young, R. 1995. Colonial Desire. London: Routledge.

Zanker, P. 1988. The Power of Images in the Age of Augustus. Michigan: University of Michigan Press. 